\title{
Design fictions: a tool for debating societal, legal and ethical aspects of personal and pervasive health systems
}

\author{
Emmanuel Tsekleves ${ }^{1}$, Andy Darby ${ }^{1}$, Anna Whicher $^{2}$, Piotr Swiatek $^{2}$ \\ ${ }^{1}$ Lancaster University, The LICA Building, Bailrigg, Lancaster, LA1 4YW, UK \\ \{e.tsekleves\} \{a.darby\} @ lancaster.ac.uk \\ ${ }^{2}$ Cardiff Metropolitan University, Llandaff Campus, Western Ave., Cardiff, CF5 2YB, UK \\ \{awhicher\} \{pswiatek\} @cardiffmet.ac.uk.
}

\begin{abstract}
The potential benefits offered by health-related technologies are counterpoised by the societal, legal and ethical challenges concomitant with the pervasive monitoring of people necessitated by such technological interventions. Through the ProtoPolicy research project we explored the production and use of design fictions as a tool for debating the societal, legal and ethical dimensions of personal health systems. Two design fictions were co-created and tested in a series of design workshops with community groups based in Lancashire and Cornwall, UK. A thematic analysis of a debate among older people from the Lancaster group on the Smart Object Therapist (SOT) design fiction highlighted societal and ethical issues relevant to personal health system design. We conclude that ethics like 'usability' may be usefully based on engagement with directly or indirectly implicated publics and should not be designed into innovation by experts alone.
\end{abstract}

Keywords: Design Fiction; Speculative Design; Personal Health Systems; legal and ethics; pervasive healthcare;

\section{Introduction}

As the ageing population of the world is increasing, so is the pace and range of technological innovation to support healthcare in our later lives. In the effort to develop the ageing well agenda, the research and business communities are exploring and developing personal health systems, with the aim of supporting independent and assisted living, and governments are introducing policies that reinforce 'ageing in place' [1]. However, the health-related benefits offered by technology (e.g. independency, better quality care) are counterweighted by the societal, legal and ethical challenges concomitant with the pervasive monitoring of people necessitated by the relevant technologies [2]. There is a need, therefore, for facilitating public engagement and discussion on the social, legal and ethical issues arising from current and, more crucially, emergent technologies in personal and pervasive health systems, and for facilitating an interaction and debate between policy makers and citizens.

In light of the above we present in this paper the ProtoPolicy research project and posit the use of design fictions as a tool for debating the societal, legal and ethical dimensions of personal health systems. ProtoPolicy was an exploratory pilot research 
project that ran from June to September $2015^{1}$. The ProtoPolicy team adopted an inclusive, collaborative and creative approach to engage a range of stakeholders across community groups and Westminster to examine how design fictions could be used to imagine the future implications of political decision-making.

\section{Related Work}

With an increasing use of personal and pervasive technologies, citizens are becoming data producers and more knowledgeable about their own health. However, citizen awareness of the level of information sharing and storage garnered in their use of personal health technologies is often low [3]. Several of the new personal health systems available offer self-health management, independent and assisted living and community healthcare benefits. They often rely on personal health data and pervasive monitoring of patients raising many ethical, legal and societal issues, which manifest as both opportunities and challenges [4], [5], [6], [7].

The eHealth Action Plan 2012-2020 [8] highlights that patient and public engagement and trust in the ethical, legal and socially considerate use of data is key to leveraging the potential of new technologies. Moreover, policy-makers in public health and other sectors are realising the interconnections between decisions in their domains. Increased participation is an ethical and societal opportunity and one increasingly valued in regulatory and legal frameworks [9]. Therefore, there is a need for processes and tools that enable and facilitate the participation of citizens and policy makers in open debate on the social, legal and ethical complexities arising from technologal intervention in personal and pervasive health systems, such as smart homes and assisted living environments.

In this paper we propose design fictions as a potential tool for facilitating citizen participation in the social, ethical and legal debates relevant to emergent technologies in healthcare. Speculative design is an approach enabling us to think about the future prospectively and critically [10]. One of its principal assumptions is the negation of the status quo and initiation of a discussion on possible worlds through confrontation with tangible object or process, the so-called design fiction. Speculative design uses design thinking tools and methodologies such as scenarios, brainstorming and rapid prototyping along with techniques borrowed from art, literature, film, psychology, philosophy, anthropology and ecology to create design fictions - provocations or 'narrative elements to envision and ex-plain possible futures for design' [11].

Design fiction is about creative provocation, raising questions, innovation, and exploration.' [12] Design fictions go beyond that 'to account for the ways in which cinematic depictions of future technologies demonstrate to large public audiences a technology's need, viability and benevolence' [13]. Therefore one of the key values of design fiction is that is uses a fictional paradigm to catalyse debate about potential futures. As a speculative design practice design fictions do not claim to predict the future; they place potential futures within our imaginative reach for consideration as to their preferability. Fundamentally they act as aids to enable users to act as research

\footnotetext{
${ }^{1}$ See http://imagination.lancs.ac.uk/activities/ProtoPolicy

${ }^{2}$ See: http://imagination.lancs.ac.uk/outcomes/Smart_Object_Therapist_Design_Fiction
} 
participants or debate participants or potentially to explore as real-world policymakers. Design fictions are concerned with progress, ideas for the better, but they take into account that better means different things to different people [14] and do not focus on implementation, but on discussing 'what-if' scenarios.

\section{Research Methodology}

A participatory design methodology [15] was used that included three stages, namely problem definition, co-creating design fictions, prototyping and testing.

In stage one, the policy and academic contexts for design negotiating political questions were explored through secondary research and an examination of the government policy documents around the theme of ageing was conducted at the time of the research project (early June 2015). This helped identify a number of related government policy initiatives (such as 'ageing in place', integrated health and social care, ageing well and several others) that could be explored in the second stage with the stakeholders. Extracts of these policies were explored in two co-design [16] workshops in Lancashire $(n=14)$ and Cornwall $(n=7)$ with community groups and older citizens. The workshops were conducted in June 2015, with participant ages ranging from 65-95. The first workshop included participants recruited from an AgeUK group and lasted half a day, whereas the second workshop included participants at a sheltered accommodation and was run over two days. A range of techniques was used to explore the use of design fictions in negotiating political questions. All speculations, concepts and ideas that emerged from the workshops were captured via audio recording, photography and short video presentations.

Stage three focused onto translating the workshop insights and co-designed speculations into design fictions. Analysing and coding the captured data the research team worked with the project collaborator Design Friction to develop a series of concepts for the design fictions. Following this two design fictions were realised and prototyped, namely the SOULAJE, a self-administered euthanasia wearable, and the Smart Object Therapist (SOT), which combines occupational health with experience in pervasive and assisted home technology to ensure that future smart home appliances correspond to user needs. The former design fiction was designed as a response to the workshop co-designers expressed needs for self-control and living with dignity and was aimed at opening further the debate around the ethical and legal aspects of technology-enabled assisted dying. The second design fiction was developed as a response to the government policies of integrated care and ageing in place and assisted living in smart homes and was aimed at extending the debate around the ethical and social aspects of personal health and pervasive technology at home and social inclusion/interaction. Given the paper focus and length limitations we will focus on the SOT design fiction in this article.

The SOT design fiction ${ }^{2}$ comprised of three documents, namely a SOT job application, the SOT intervention report and prescription and a short video breakfast TV style article featuring the SOT and a smart object home user. Set in the year 2020

\footnotetext{
${ }^{2}$ See: http://imagination.lancs.ac.uk/outcomes/Smart_Object_Therapist_Design_Fiction
} 
the SOT interview design fiction sets the speculative scene by presenting the skills a SOT is expected to have in the envisaged integrated health and social care service model, where older people age at home supported by an array of smart appliances. The job of a SOT is not limited to fixing technical faults but is centred around recalibrating human behaviour to facilitate interaction between smart objects and their owners. The SOT intervention report and prescription design fictions present a possible world where the SOT has been called in to intervene between the homeowner and smart home to resolve an issue. The SOT design fiction creates an appropriate and open environment for debate by exploring 'misbehaving' smart home technology, a smart self-refilling fridge that confuses the homeowner for his grandson.

\section{Findings and Discussion}

Following their development the design fictions and the concepts they encompassed were explored by seeking feedback from policy makers at a policy engagement event in Westminster Palace in London in July 2015 and from citizens at a co-design workshop in Lancaster in September 2015. The event at Westminster and the semistructured interviews with civil servants and a politician were focused on the barriers and opportunities to using design methods to negotiate political issues with citizens. The co-design workshop, which was run with the same group that initiated the design fictions, was focused on in-depth discussion of the design fictions, the underpinning speculations and the ethical, societal and legal issues they presented. In this short paper, we focus on an analysis of the citizens' discussions in the workshop.

The thematic analysis of discussion that followed the presentation of the SOT design fiction, as well, as the visual material collected during the workshop activities, revealed a number of ethical, legal and societal concerns that participants discussed. In terms of the societal aspects of smart home technology for health systems, workshop participants expressed the need and desire for supporting older people to live independently, especially ones with long-term health conditions.

'I have to say although I feel quite hostile to this I have also seen a more primitive version of this work well for somebody living independently with dementia. Their house was set-up with a lot of alarms, so that if she opened the door like at night time and didn't come back straight away then the police would be informed, you know a lot of things like that which meant that she was able live independently for much longer that she would have done otherwise and I suppose this is an extension of the same idea' [Jane]

Some participants used this discussion to also talk about robotics in care but recognised that there is value in health systems that do not diminish independence. In fact reducing independence was a concern that several people raised as a result of living in a home environment over-reliant on technologies. Related to this was a lengthy discussion on social isolation being a potential result of peoples' over-reliance on smart home healthcare living environments. Instead of encouraging people to stay more physically active by going out and reinforcing social interactions between people, there was an expression of concern towards encouraging more sedentary and self-isolation behaviours by replacing human contact with 'smart' technology. 
'An unwanted side effect of that sort of technology is that it would actually keep people in their homes rather than encouraging them out of their home on their day-to-day basis. This would have impact on their health and mental health, it's about interactions, about being stimulated all sort of other things not met by technology' [Maggie]

The SOT design fiction facilitated a discussion around the ethical and legal aspects of similar personal health systems. Trust in the technology to perform as expected and technology replacing humans in terms of healthcare services was a key topic of debate. With regards to the specific SOT design fiction scenario people questioned the training and education background that such a techno-occupational therapist professional would need to have. Questions were raised as to whether such a role would have a person-centred approach and whether the focus will be placed on the human or the smart and personal health technology.

'What comes first? Is it an all in one house you move into or does the therapist come first to access your needs?' [Laura]

This led into discussions regarding the financial and legal aspects of personal health systems. A theme, which was extensively discussed, was that of the financial and legal framework of service provision. Questions were raised as to who would pay for the technology installation, home adaptation, technology support, as well as perceived cost and long-term economical value.

'This is forwarding thinking of how we are going to carry on with the age of people going to $90 \mathrm{~s}$ and 100s, how can we stop hospital admissions, how can we save money, even if all this seems fantastical' [Sam]

'By the time you paid for all this technology, would it not be cheaper to have somebody pop round for few hours every day' [Claire]

Additional thought was given to accessibility of such future services to the public if a privately funded model is to be selected. A few participants even discussed possible financial models involving big supermarkets (linking it to food restocking), which created discussion around sharing of personal data, habits and personal health records.

'You can see how supermarkets the likes of Tesco's would love to something like this. They could restock your [smart] fridge and in the process find out all about your food likes and habits and even your health condition' [Paul]

This led the discussion back to the ethical implications related to agency, personal choice and control between personal health home systems and their users.

'This is a clinical solution... you are a diabetic so it's looking at sugar levels in foods, whereas the wheelchair food service does put that on you it's up to you to make the choice, your informed decision' [Sam] 'Thank god for that!' [Jenny] 'I tell myself what I want to eat I'm not going to ask any [smart] fridges' [Pam]

\section{Conclusion}

This paper has argued that research that drives innovation through analysis of ethical, legal and social challenges and opportunities is needed more than ever. Building upon qualitative participatory and speculative design research, it has become clear that, 
ethics like 'usability' may be usefully based on engagement with directly or indirectly implicated publics and should not be designed into innovation by experts alone.

The design fiction generated a rich discussion on the societal, legal and ethical implications of the presented concept related to personal health systems for independent living. The designers/facilitators used the design fictions as props to initiate discussion and workshop participants used them as prompts to form a debate. Most of the workshop participants employed personal stories and lived experiences to relate to several of the societal and legal aspects of the introduction of smart home technology for healthcare. It was interesting to observe through the recorded data that there was a diversity of views expressed. Also, it is notable that participants who were initially skeptical warmed to the principles underpinning the personal health system concept as a result of working through the socio-ethical issues in debate.

Acknowledgments. The authors would like to thank all workshop participants, the Age UK Lancashire, all members of the ProtoPolicy project. The research work was supported by the Arts and Humanities Research Council (Grant no: AH/N003810/1).

\section{References}

1. Dishman, E.: Inventing wellness systems for aging in place. Computer. 37, 34-41 (2004).

2. Coughlin, J.F., D'Ambrosio, L.A., Reimer, B. and Pratt, M.R., August. Older adult perceptions of smart home technologies: implications for research, policy \& market innovations in healthcare. In EMBS 2007. 29th Annual International Conference of the IEEE (pp. 1810-1815). IEEE (2007).

3. Batchelor, R., Bobrowicz, A., Mackenzie, R., Milne, A.: Challenges of ethical and legal responsibilities when technologies' uses and users change: social networking sites, decision-making capacity and dementia. Ethics and Information Technology. 14, 99-108 (2012).

4. Anthony, D., Henderson, T., Kotz, D.: Privacy in Location-Aware Computing Environments. IEEE Pervasive Comput. 6, 64-72 (2007).

5. Brown, I., \& Adams, A. A. The ethical challenges of ubiquitous healthcare. International Review of Information Ethics, 8, 53-60 (2007).

6. Dodge, M., Kitchin, R.: 'Outlines of a world coming into existence': pervasive computing and the ethics of forgetting. Environment and Planning B: Planning and Design. 34, 431-445 (2007).

7. Kim, J., Beresford, A.R. and Stajano, F., Towards a security policy for ubiquitous healthcare systems. In Ubiquitous Convergence Technology. 263-272. Springer Berlin Heidelberg (2007).

8. Digital Single Market,:eHealth Action Plan 2012-2020: Innovative healthcare for the 21st century Digital Single Market - European Commission, https://ec.europa.eu/digital-agenda/en/news/ehealthaction-plan-2012-2020-innovative-healthcare-21st-century.

9. Irvin, R. A., \& Stansbury, J. Citizen participation in decision making: Is it worth the effort? Public administration review, 64(1), 55-65. (2004).

10. Hales, D.: Design fictions an introduction and provisional taxonomy. Digital Creativity. 24, 1-10 (2013).

11. Tanenbaum, J., Tanenbaum, K. and Wakkary, R. Steampunk as design fiction. In Proceedings of the SIGCHI Conference on Human Factors in Computing Systems (pp. 1583-1592). ACM. (2012)

12. Bleecker, J. Design Fiction. A short essay on design, science, fact and fiction. Near Future Laboratory. (2009).

13. Kirby, D.: The Future is Now: Diegetic Prototypes and the Role of Popular Films in Generating Real-world Technological Development. Social Studies of Science. 40, 41-70 (2009).

14. Dunne, A., Raby, F. Speculative Everything. Design, Fiction, and Social Dreaming. The MIT Press: Cambridge, MA (2013).

15. Simonsen, J., Robertson, T.: Routledge international handbook of participatory design. Routledge, New York (2013).

16. Sanders, E., Stappers, P.: Co-creation and the new landscapes of design. CoDesign. 4, 5-18 (2008). 